\title{
0 trabalho da mulher e as negociações coletivas
}

SOLANGE SANCHES

eVERa LUCIA MatTAR GEBRIM

A INTEN SIFICAÇÃo da presença feminina no mercado de trabal ho tem ocorrido em uma conjuntura político-econômica extremamente adversa, que se traduz, para todas as pessoas que procuram ocupação, na escassez e má qualidade dos postos de trabal ho.

A busca da estabilização, inicialmente, das contas externas, na primeira metade da década de 1980, e depois da inflação, de 1985 até 1994, somada às mudanças na política econômica nos anos de 1990, como a privatização e a abertura comercial e financeira da economia nos governos de Fernando Collor e de Fernando $\mathrm{H}$ enrique $\mathrm{C}$ ardoso, teve um efeito perverso sobre o PIB e sobre o nível de emprego. D urante o Plano R eal, a forte competição levou as empresas a cortar postos de trabalho e a flexibilizar os vínculos trabal histas, em nome da reestruturação produtiva e da sua sobrevivência no mercado.

No mercado de trabalho, o que se observou, a partir dos anos de 1990, foi o crescimento do desemprego, a expansão do assalariamento sem carteira e dos trabalhadores autônomos, a redução dos rendimentos e da contratação com carteira assinada e de benefícios garantidos em lei. 0 resultado sobre as famílias foi a diminuição da qualidade de vida dos indivíduos e o aumento do desemprego do chefe do domicílio, obrigando os demais membros da família a buscar um posto de trabal ho para aumentar a renda familiar.

Além disso, as mudanças na composição das famílias, tradicionalmente chefiadas por homens, contribuíram para esse movimento. 0 crescimento de famílias com chefia feminina, seja pela dissolução do casamento, seja pela morte do marido ou, ainda, pela simples opção de viverem sozinhas, também impeliram a mulher para o mercado de trabalho.

No entanto, justificar a presença da mulher na força de trabal ho por motivos meramente econômicos significa reduzir as conquistas por elas alcançadas. Essa inserção se deve, igualmente, ao movimento de emancipação feminina e à busca de direitos iguais na sociedade.

A pesar de crescente, a participação feminina no mercado de trabalho tem sido marcada por uma série de adversidades que se somam às decorrentes da difícil situação so cioeconômica que o país tem atravessado nas últimas décadas. Para as mulheres, as dificuldades colocam-se desde sua forma de inserção no mercado, 
que passa por baixos salários, ocupação de postos precários e discriminação na contratação e ascensão profissional, até a necessidade de conciliar trabalho e cuidados com filhos e casa, responsabilidades que Ihes são tradicionalmente atribuídas.

\section{A mulher no mercado de trabalho no Brasil}

No Brasil, em 2001, 34.852.764 mulheres estavam no mercado de trabaIho como ocupadas ou desempregadas, número equival ente a $41,9 \%$ da População Economicamente Ativa (PEA), segundo dados da Pesquisa $\mathrm{N}$ acional por A mostra de Domicílio (PN AD), realizada pelo Instituto Brasileiro de Geografia e Estatística (IBGE). Em 1995, o percentual era menor - correspondia a 40,1\% da PEA - e a força de trabal ho feminina ficava em 29.820 .663 pessoas.

Q uase metade - cerca de $46 \%$ do total das mulheres que estavam ocupadas em 2001 - trabal hava como assalariada, forma de trabalho que, quando envolve vínculo de trabalho formal representado pela carteira assinada, garante à mulher ocupação de melhor qualidade, com mais garantias e benefícios. No entanto, é alto o percentual de mulheres que se ocupava na condição de empregadas domésticas $(18,3 \%)$, de autônomas $(16,3 \%)$ ou mesmo que exercia trabalho sem remuneração $(9,8 \%)$, o que evidencia a vulnerabilidade do trabalho feminino.

No caso dos homens, a estrutura de ocupação é diferente da feminina. $M$ ais da metade dos ocupados trabal ha como assalariado e sua presença no serviço doméstico é pouco significativa. É maior, também, a parcela de homens que trabalha como autônomo.

U m grande contingente de mulheres reproduz, no mercado de trabalho, atividades semelhantes àquelas realizadas no âmbito doméstico, educando crianças ou cuidando de idosos e doentes, trabalhando, sobretudo, em setores ligados à educação e à saúde. Os dados mostram que, em 2001, os setores que mais contaram com o trabalho feminino foram os que englobam as atividades que têm as mesmas características das funções exercidas no lar, como prestação de serviços e atividade social que, juntas, alocaram $48,7 \%$ das ocupadas. Também é significativa a participação da mulher no comércio de mercadorias: 14,7\%

Em 2001, ainda se mantém elevada a proporção de mulheres que atua na agricultura e pecuária (16,2\%). O s homens têm maior presença em setores com atividades mais estáveis e melhores salários, como a indústria de transformação. São ainda absolutamente majoritários na indústria da construção e encontram-se em maior proporção nas atividades rurais.

\section{D esigualdades nos mercados de trabalho metropolitanos}

A situação das mulheres no mercado de trabalho é revelada por meio de três indicadores: os de inserção, de qualidade dos postos ocupados e de nível de remuneração.

a) Dificuldades de inserção - O desemprego se tornou um dos maiores problemas sociais na década de 1990 e é óbvia a ligação entre a capacidade de 
gerar novos postos de trabalho e o nível de atividade econômica. Como a economia brasileira, no período, teve desempenho medíocre, as taxas de desemprego foram crescentes para ambos os sexos.

As dificuldades para obtenção de emprego, porém, são maiores para as mulheres do que para os homens, tanto que suas taxas de desemprego são sistematicamente superiores às masculinas. 0 s resultados da Pesquisa de E mprego e D esemprego (PED) referentes às regiões metropolitanas de Belo $\mathrm{H}$ orizonte, Porto Alegre, Recife, Salvador, São Paulo e do D istrito Federal, realizada pelo convênio Dieese/ Seade, M TE/ FAT e entidades regionais, confirmam esse desempenho em todas as localidades.

Em 2002, em todas as regiões pesquisadas, as taxas de desemprego total das mulheres são superiores às verificadas para os homens. Q uando se desmembra o desemprego segundo o tipo, porém, al gumas situações diferenciadas aparecem.

As taxas de desemprego aberto ${ }^{1}$ são sistematicamente superiores para as mulheres: em média, a diferença entre as taxas de homens e mulheres é de $5 \%$

Q uando se trata, porém, do desemprego oculto - casos em que algumas situações podem mascarar o desemprego - há comportamentos diferentes entre as taxas dos homens e das mulheres.

0 desemprego oculto pelo trabalho precário é uma das formas consideradas por este tipo de desemprego ${ }^{2}$. Como a maioria dos chefes de família- pessoas que, de modo geral, não podem ficar sem ocupação alguma, ainda que eventual é constituída por homens, indivíduos do sexo masculino são majoritários entre os componentes desta taxa.

U ma segunda categoria refere-se ao desemprego oculto pelo desalento ${ }^{3}$. As mulheres são majoritárias nessa categoria, pois, em geral ocupam-se de afazeres domésticos, enquanto aguardam uma ocupação.

Além de suas taxas de desemprego serem mais elevadas, as mulheres costumam ficar longos períodos sem conseguir uma colocação.

b) A vulnerabilidade na inserção feminina - As dificuldades que as muIheres enfrentam para se inserir no mercado de trabalho refletem-se na qualidade dos empregos por elas obtidos. 0 trabalho feminino encontra-se, em maior proporção, em postos de trabalho vulneráveis, representados pelo assalariamento sem carteira assinada, trabal ho doméstico, autônomos que trabalham para o público e trabalhadores familiares.

O percentual de mulheres em situação vulnerável é sistematicamente superior ao de homens, em todas as regiões pesquisadas, chegando a atingir cerca de metade do contingente feminino ocupado nas áreas metropolitanas de Salvador e Recife, em 2001. Entre os homens, essa taxa atinge o mais alto patamar em Recife: 35,6\% Essa situação deve-se, especialmente à presença maciça das mulheres no emprego doméstico e, de forma menos expressiva, nos trabalhos familiares. 
Já os homens, dentre as categorias com vínculos mais vulneráveis, encontram-se mais entre autônomos que trabalham para o público e assalariados sem carteira de trabalho assinada.

c) A desigualdade na remuneração entre os sexos - O s rendimentos da mulher no mercado de trabal ho são sempre inferiores aos dos homens, mesmo quando exercem a mesma função e têm a mesma forma de inserção. $\mathrm{N}$ em mesmo a maior escolaridade média feminina elimina essa diferenciação, indicando clara discriminação em relação ao seu trabalho. Os dados da PED indicam que, em média, a mulher recebe cerca de $66 \%$ do rendimento dos homens.

Já entre os assalariados, para quem as relações de trabalho são mais formais, em especial para aqueles com carteira assinada, a diferença entre as remunerações é menor e o salário da mulher equivale, em média, a 85\% do valor recebido pelos homens.

Como as mulheres têm, tradicional mente, jornada de trabalho diferenciada da masculina, a análise dos rendimentos recebidos por hora revela, de forma mais precisa, as desigual dades entre remunerações.

A análise desse indicador demonstra que, independentemente do nível de instrução, o rendimento por hora das assalariadas é menor do que o dos homens, em todas as regiões metropolitanas.

I sso significa que, apesar de o nível de instrução ser um fator fundamental de diferenciação salarial, a escolaridade da mulher não garante um salário melhor.

\section{A negociação coletiva de trabalho e as questões referentes ao trabalho da mulher}

A evidente desigualdade das mulheres no mercado de trabalho faz com que esse tema esteja cada vez mais presente nas discussões dos diversos segmentos da sociedade, notadamente no movimento sindical.

M uito já se avançou para o entendimento do problema e grande tem sido o esforço para a conscientização dos empregadores da necessidade de aceitar o trabalho feminino como sendo de qualidade idêntica ao masculino, e assim, minimizar as diferenças.

M as, apesar dos avanços obtidos, há, ainda, um longo caminho a se trilhar para que os indicadores possam revelar condições de igualdade entre os sexos no mercado de trabalho.

U m dos espaços fundamentais para a conquista de garantias ao trabal ho da mulher e a busca da eqüidade de gênero é o da negociação coletiva de trabalho, no qual patrões e trabalhadores discutem problemas referentes às relações de trabalho e estipulam normas para a regulamentação dos diversos aspectos dessa relação.

Para traçar um panorama da negociação de questões pertinentes ao trabaIho da mulher, o Dieese - Departamento Intersindical de Estatística e Estudos 
Sócio-E conômicos - realizou um estudo sobre cláusulas relativas ao tema constantes de acordos e convenção coletivas de trabalho firmados por algumas das mais importantes categorias profissionais no processo de negociação coletiva de trabalho no Brasil ${ }^{4}$.

A pesquisa baseou-se no SACC - D ieese - Sistema de Acompanhamento das Contratações Coletivas, desenvolvido para o cadastramento de documentos resultantes do processo de negociação coletiva de trabal ho, que definem as condições de trabalho das diversas categorias profissionais.

Foram analisados 94 documentos por ano, entre 1996 e 2000, abrangendo, aproximadamente, trinta categorias profissionais pertencentes aos setores industrial, comercial e de serviços de catorze unidades da Federação das diferentes regiões geográficas do país.

As cláusulas localizadas foram agrupadas em sete temas: gestação, maternidade/ paternidade, responsabilidades familiares, condições de trabalho, processo e exercício do trabalho, saúde da mulher e eqüidade de gênero.

Garantiasrelativasà gestação - No grupo relativo à gestação, foram analisadas as cláusulas que têm por objetivo preservar a saúde da mulher e da criança durante a gravidez, por meio de direitos concedidos às trabalhadoras. Foram, então, incluídas as medidas pactuadas para garantir condições de trabal ho compatíveis com a gestação e propiciar seu acompanhamento e desenvolvimento satisfatório, além das que procuram descaracterizar a gravidez como impeditivo para a contratação ou manutenção do emprego da trabalhadora.

N este grupo estão englobadas cerca de $20 \%$ do total de garantias às mulheres registradas pelo SACC-D ieese. A mais freqüente se refere à etabilidade da gestante, negociada por $85 \%$ das catego rias profissionais pesquisadas.

A proximadamente $60 \%$ das categorias que prevêem essa estabilidade em seus contratos reafirmam as disposições legais com relação a sua duração, ou seja, de cinco meses após o parto. O s outros $40 \%$ ampliam o prazo previsto em lei em períodos que variam de trinta a 120 dias.

O utra garantia negociada em favor da trabal hadora gestante é a que assegura função compatível com a gestação, presente nos contratos de doze das 94 categorias profissionais analisadas (13\%), o que demonstra ainda ser pequena a sua incidência.

N essas cláusulas não há avanço em relação às determinações legais. A mudança de função da trabalhadora gestante está condicionada a casos excepcionais, como local de trabalho insalubre ou prejudicial à gestação; atividade que ofereça riscos; condições de trabal ho incompatíveis; necessidade de saúde; exigências de ordem física, sem que sejam definidos indicadores que possam caracterizar essas situações.

Além dessas, foram localizadas algumas garantias de li beração da gestante antes do término da jornada de trabalho. 
Esta é uma das conquistas dos trabalhadores que não tem como referência a legislação brasileira, isto é, trata-se de uma inovação resultante do processo de negociação coletiva.

Entretanto, apenas três categorias profissionais, no universo pesquisado, incluíram-na em seus contratos coletivos de trabalho.

Também em um número restrito de categorias profissionais (quatro) foi assegurada a dispensa da gestante para exames prénatal. N este caso, cabe ressalvar que posteriormente a esta conquista na negociação direta entre as partes, a legislação brasileira ${ }^{5}$ passou a assegurá-la.

I gualmente em quatro contratos coletivos registrados no SACC-D ieese, foram incluídas cláusulas sobre atestado médico de gravidez, cada uma com um objetivo diferente. Em um caso, reconhece-se a validade do atestado do sindicato como prova de gravidez; em outro, prevê-se o ressarcimento dos gastos com ele efetuados.

H á ainda um que proíbe a realização de teste de gravidez pré-admissional e outro que estabelece a obrigatoriedade de sua realização na demissão da trabaIhadora.

Ainda foi localizada uma cláusula firmada por uma única categoria profissional que assegura primeiros so corros para o parto, através de transporte de urgência, para locais apropriados.

Por fim, também uma única categoria profissional garante à gestante acesso a estudo elaborado pelo sindicato sobre os riscos da expos ção junto aos ter minais de vídeo no período da gestação e a possibilidade desta romper o vínculo empregatício sem cumprimento do aviso prévio legal.

É interessante observar que todas as cláusulas que têm por finalidade dar garantias relativas à gestação referem-se apenas à trabal hadora, excluindo o futuro pai do processo de gestação. Garantias como o abono de faltas do pai para acompanhar a gestante nos exames pré-natais ou sua estabilidade no emprego durante a gravidez da companheira não foram negociadas nos contratos coletivos pesquisados.

Garantiasà maternidade/ paternidade- As cláusulas incluídas nesse grupo são as que se relacionam à compatibilização entre o exercício do trabalho e os cuidados necessários à criação e acompanhamento dos filhos, compreendendo as garantias a pais e mães desde o momento do nascimento da criança.

Também entre as cláusulas relativas à maternidade/ paternidade, a existência de legislação norteia a inclusão do tema nos contratos. As garantias asseguradas por lei são as mais difundidas nos diversos contratos coletivos.

A pesquisa real izada no SACC - $D$ ieese demonstra que, depois da estabilidade à gestante, as cláusulas sobre guarda dos filhos (creche) são as mais freqüentes no que se refere às questões de gênero, negociadas por 58 categorias profissionais. I sso significa que aproximadamente $62 \%$ do painel analisado incluem em seus contratos garantias sobre esse tema. 
Q uanto ao conteúdo, cerca de $20 \%$ das categorias profissionais que incluem em seus contratos coletivos de trabal ho cláusula so bre creche declaram que deverá ser cumprida a legislação sobre o tema. O s $80 \%$ restantes explicitam quais medidas serão adotadas como alternativa à obrigatoriedade das empresas de instalarem berçários ou manterem convênios, conforme os dispositivos legais.

D essas, a grande maioria prevê reembolso parcial dos gastos efetuados.

Em um grande número de contratos, os beneficiários são somente as mães trabal hadoras. Alguns prevêem sua extensão aos pais que se encontram em condições especiais separados, divorciados ou viúvos, desde que detenham a guarda dos filhos e que não estejam casados ou vivendo em concubinato. A penas quatro categorias profissionais garantem o pagamento desse benefício a todos os trabalhadores.

H á uma grande variedade quanto aos valores e períodos durante os quais serão ressarcidos esses gastos. A lguns dos contratos prevêem seu pagamento apenas até o prazo previsto pela legislação, ou seja, até os seis meses de vida da criança, mas a grande maioria o amplia. Foram localizadas garantias de extensão do prazo desde que a criança complete nove até 83 meses.

A maior parte das cláusulas estabelece limite máximo para a restituição dos valores gastos pelas trabalhadoras com creche. Poucos são os contratos coletivos que determinam a cobertura integral dos gastos efetuados.

O utra garantia que apresenta alta freqüência na negociação ( $50 \%$ do painel) é o abono de faltas para acompanhamento de filhos.

Q uase a totalidade das cláusulas aqui registradas relaciona-se ao acompanhamento dos filhos em questões de saúde. D essas, cerca de $60 \%$ referem-se exclusivamente à internação hospitalar e os outros $40 \%$ a ausências relativas a doenças. A maioria as prevê para consultas médicas.

Q uanto aos beneficiários do abono de faltas, diferentemente das outras garantias relativas à maternidade/ paternidade, a maioria das cláusulas reporta-se a todos os trabalhadores da categoria, sem discriminação de sexo. Do restante, parte 0 assegura ao pai apenas quando a mãe não puder acompanhar o filho e, em menor número, a garantia é concedida apenas às mães.

Em aproximadamente dois terços dos contratos, conquista-se 0 abono da falta, sem prejuízo do salário. Em um terço é negociado apenas o desconto das horas de ausência, sendo preservados o descanso semanal remunerado, férias, feriados e $13^{\circ}$ salário.

A idade limite dos filhos a serem acompanhados é bastante variável de um contrato para outro. Algumas cláusulas a estabelecem em até seis, sete, dez, doze e catorze anos. Em uma delas, a garantia é válida para filhos menores de idade. E $m$ alguns dos contratos, ainda, não há especificação da idade máxima do filho para que a ausência seja justificada. É importante registrar que cerca de $20 \%$ das cláusulas mencionam que, no caso de filhos excepcionais, deficientes ou inválidos, não há limite de idade. 
H á ainda um caso em que, diante da internação de filhos, além do abono de falta de um dia útil, é concedido o direito de flexibilização do horário de trabalho, de comum acordo com a empresa, mediante compensação posterior.

Por fim, devem ser destacadas duas garantias: uma que assegura às mães trabalhadoras, que tenham filhos cursando o primeiro e segundo graus, o abono das horas de ausência ao trabalho, quando convocadas para reuniões escolares que se realizem em horário coincidente com o de sua jornada de trabal ho.

A outra garante a concessão de folgas, na medida do possível, nas datas de aniversário de filhos e cônjuges.

Em um menor número de contratos (nove), constam cláusulas referentes, especificamente a garantias a trabal hadores com dependentes portadores de deficiência.

A maioria dessas cláusulas assegura cobertura de gastos com educação. D essas, parte estende o auxílio-creche negociado aos dependentes portadores de deficiência e parte menciona explicitamente 0 reembolso de despesas efetuadas com educação especializada.

M erece destaque uma cláusula que garante a trabalhadores que recebem até três salários mínimos, reembolso de $50 \%$ das despesas com medicamentos e/ ou tratamento profissional ou hospitalar de filho excepcional ou deficiente físico, limitado a um piso da categoria.

Também é importante citar a conquista, por uma categoria profissional, de flexibilidade de horário (desde que de comum acordo com a empresa e compensação de horário) ao trabalhador com dependente deficiente.

Ainda dentro do grupo maternidade/ paternidade, foram negociadas, com freqüência significativa, cláusulas relativas à licença-maternidade, constantes nos documentos firmados por 21 categorias profissionais ( $22 \%$ do total).

A grande maioria delas não apresenta avanços em relação aos dispositivos legais, restringindo-se a transcrever as determinações referentes à duração do período de afastamento, que é estipulado em 120 dias.

Em al guns casos, regulamenta-se o cálculo do salário-maternidade das trabalhadoras comissionadas. Em outros, estendem-se os benefícios indiretos às mães em licença.

O utra garantia bastante negociada neste grupo é a de licença-paternidade: 33 categorias profissionais a incluem em seus contratos, o que corresponde a cerca de $35 \%$ do total examinado.

I gualmente aqui, a maioria dos contratos coletivos que trata da licença reafirma as disposições legais, ou seja, direito à licença ao pai por cinco dias, em virtude do nascimento do filho, sendo que grande parte especifica que estes devem ser consecutivos. Algumas cláusulas prevêem o gozo da licença no decorrer da primeira semana de vida da criança e uma, durante as duas primeiras semanas. 
Embora em pequeno número, algumas cláusulas registradas avançam em relação à legislação quanto ao prazo da licença-paternidade, estendendo-o.

Algumas poucas categorias profissionais (seis) asseguram estabilidade ao pai, garantia não prevista em lei. 0 perío do da estabilidade é estipulado em trinta, sessenta ou noventa dias, a depender do contrato.

Ainda foram localizadas nos contratos de dezessete categorias profissionais ( $18 \%$ do total), algumas garantias às trabalhadoras lactantes, incluindo a prevista em lei, de direito a local para amamentação e dois intervalos, durante a jornada de trabalho, para esta finalidade.

A maior parte dos contratos prevê a possibilidade de acumular os dois intervalos para amamentação, de meia hora cada, em um único intervalo de uma hora.

Em dois casos há avanços em relação à legislação, no que se refere ao prazo: um esten de a garantia até que a criança complete nove meses de idade, ressalvando que, se houver prescrição médica, este período poderá ser dilatado e outro assegura a redução da jornada diária de trabalho da mãe até que o filho complete doze meses.

Ainda há uma categoria profissional que amplia os dois intervalos para 45 minutos cada um, já previsto o deslocamento da mãe.

H á também duas categorias profissionais que estabelecem a extensão da licença-maternidade para fins de amamentação. E m um caso, está prevista a possibilidade de a lactante entrar em licença não remunerada por até noventa dias após o término da licença- maternidade e, em outro, a ampliação da licençamaternidade em duas semanas, conforme o disposto na CLT, mediante atestado médico.

Por fim, dada a especificidade do trabalho, é assegurado à aeronauta, se esta assim o desejar, a dispensa de reserva, sobreaviso e de programação que obrigue a pernoite fora da base. Estipula-se, ainda, que, durante esses seis meses, a cota mensal de horas de vôo deve ser limitada à correspondente ao salário garantido e que os vôos devem ser programados de comum acordo com o setor incumbido da organização da escala de serviço, sendo que a jornada de trabalho não poderá exceder oito horas. Ainda é garantida à mãe uma folga semanal a mais do que as folgas regulamentares.

Para finalizar o grupo de cláusulas relativas à maternidade/ paternidade, foram localizadas e analisadas as que determinam garantias aos trabalhadores adotantes.

No período analisado, a legislação trabalhista, embora a sociedade reconheça a importância dessa medida e a necessidade de incentivos para sua prática, não assegurava garantias aos pais quando da adoção de filho ${ }^{6}$.

No total, 35 categorias profissionais acompanhados pelo SACC-D ieese estendem uma ou mais das garantias relativas à maternidade/ paternidade aos pais e mães que adotarem crianças legalmente. 
D essas, a grande maioria refere-se à licença à mãeadotante, constando dos contratos coletivos de trabalho de 31 categorias profissionais (33\% do total).

Q uanto ao conteúdo, é assegurada às trabalhadoras licença-remunerada em caso de adoção de filhos. 0 prazo de duração dessa licença é bastante variável e condicionado à idade da criança a ser adotada. A esmagadora maioria das cláusulas prevê um período inferior aos 120 dias determinados por lei para a gestante. A penas um dos contratos coletivos observados garantem 120 dias de licença à adotante, restrito à adoção de crianças de até trinta dias.

$\mathrm{N}$ a maior parte das cláusulas, verifica-se a garantia de trinta dias de licença para mães que adotarem filhos de até seis meses. Entretanto, a depender do contrato, a duração dessa licença é estabelecida entre dois e 120 dias, combinada com a idade da criança, que varia de um mês a seis anos. Foram registradas licenças de dois, sete, quinze, trinta, 45, sessenta, noventa, 92 e 120 dias, no caso de adoção de crianças de até um mês; de três meses, para crianças de seis meses, um ano, dois anos, cinco anos e seis anos. N os contratos coletivos de cinco categorias profissionais, o prazo da licença é escalonado, superior para a adoção de crianças mais novas e inferior para a adoção de crianças mais vel has. Ainda foram localizados três casos nos quais a licença expira no momento em que a criança completar um determinado número de dias e dois que a fixam em trinta dias, sem mencionar a idade da criança.

Em número bastante inferior (quatro), é estendido ao pai adotanteo mesmo prazo de licença concedido ao pai biológico.

Também é bastante reduzido o número de contratos que prevêem estabilidade para adotantes. $D$ as oitenta categorias profissionais que incluem cláusulas de estabilidade à gestante em seus contratos coletivos, apenas cinco conquistam garantia temporária no emprego para as mães adotantes. Em um único caso, concede-se ao pai o mesmo prazo de estabilidade previsto para a mãe (noventa dias).

São também poucas as cláusulas que mencionam a extensão do direito à creche ou do reembolso das despesas com creche a os filhosadotivos. D as 58 categorias profissionais que negociam alguma garantia com relação à creche, treze referem-se também à adoção.

Ainda foi registrada uma categoria profissional, dentre as 94 que compõem o SACC -D ieese, que assegurou, em al gumas de suas convenções coletivas, como auxílio-adoção ${ }^{7}$, o pagamento de uma quantia equivalente a um salário-base, no mês de comprovação da adoção.

$\mathrm{N}$ esse grupo, foram observados poucos avanços em relação às determinações legais, já que as cláusulas asseguradas reforçam matérias já previstas em lei, reportando-se quase que exclusivamente às mulheres. São raros os casos em que se explicitam garantias idênticas a homens e mulheres, o que, na prática, atribui às mães maior responsabilidade na criação dos filhos. 
Facilidades para o desempenho de responsabilidades familiares - Também foram analisadas cláusulas que concedem garantias aos trabalhadores em relação à vida familiar, no que se refere a situações que requeiram sua presença ou na extensão de benefícios a seus dependentes. Esse grupo responde por cerca de $15 \%$ do total de garantias referentes ao trabalho da mulher e às questões de gênero.

U ma das cláusulas mais difundidas neste tema é a garantia de li ber ação do trabalhador para acompanhamento de cônjugesel ou familiares que dele necessitarem. O bserve-se que, ao contrário do que ocorreu nos grupos anteriormente analisados, a cláusula mais freqüente aqui não tem base na legislação, resultando da negociação direta entre trabalhadores e patrões, dado que a legislação brasileira não faz referência a esse direito.

No SACC -D ieese, foram localizadas 26 categorias profissionais ( $28 \%$ do total) que conseguiram algum tipo de garantia nesse sentido. A totalidade destas cláusulas, porém, refere-se a motivos de saúde, com uma exceção, na qual é assegurada ao trabalhador folga no dia de seu aniversário, de seus filhos e do cônjuge.

$\mathrm{N}$ a grande maioria dos casos, é assegurada a liberação do trabalhador para acompanhamento do cônjuge em internação hospitalar, sem prejuízo do salário. E $m$ apenas dois casos é garantida somente a liberação, sem a respectiva remuneração.

Em cerca de $60 \%$ das cláusulas, 0 abono é limitado a uma falta. Foram também observados abonos de dois dias (na internação e na alta), de três dias (na internação, no dia da cirurgia e na alta) e pelo número de horas indispensáveis à internação.

Embora quase $80 \%$ das garantias refiram-se apenas ao cônjuge, há as que se estendem à internação de pai e mãe. Em um caso, assegura-se o acompanhamento para tratamento médico fora do domicílio de pessoa da família em primeiro grau.

Além dessa, uma categoria profissional conquista a possibilidade de flexibilização do horário de trabal ho durante o período de internação de cônjuge, ascendentes e descendentes.

Também nesse grupo, 23 ( $24 \%$ do total) categorias profissionais que compõem o SACC -D ieese incluíram em seus contratos coletivos cláusulas que asseguram al guma garantia em relação aos gastos com a educação de filhos e dependentes, que podem ser classificadas em cinco tipos: empréstimo, auxílio, repasse do salário-educação diretamente ao trabalhador, convênios para aquisição de material escolar e bolsas de estudos.

No que se refere a empréstimos, três categorias profissionais acordaram a garantia de um empréstimo anual para compra de material escolar e uniforme ou para matrícula dos filhos e dependentes dos trabalhadores, a ser devolvido de forma parcelada. 
Q uanto aos auxílios, sete categorias asseguraram o reembolso parcial das despesas efetuadas com a matrícula, taxas e material escolar.

$\mathrm{N}$ este caso, duas catego rias registraram conquistas que merecem destaque. U ma delas, além de um auxílio em dinheiro, assegurou um "kit material escolar" a cada um dos filhos estudantes. A outra acrescentou à garantia de financiamento de $30 \%$ do valor do material escolar, a ser pago em três vezes, um subsídio de $50 \%$ dos gastos efetuados com material escolar e uniformes dos filhos.

Já o salário-educação foi mencionado nos contratos coletivos de seis das categorias profissionais analisadas. E $m$ uma, é garantido o repasse direto do salário-educação aos empregados. Para as demais, há a recomendação de que as empresas utilizem-se do benefício para a concessão de bolsas de estudos de 1 o grau em escolas particulares para os filhos dos trabalhadores ou que adotem as medidas necessárias para seu repasse.

Q uanto às bolsasde estudo, a totalidade dos contratos firmados por professores que constam do SACC - D ieese prevêem desconto ou gratuidade para os dependentes dostrabal hadores nos estabelecimentos de ensino em que estes lecionam.

Além da educação, também a assistência à saúde é um dos temas que não está previsto na legislação brasileira e compõe a pauta da negociação trabalhista.

No material analisado, 23 categorias profissionais incluem em seus acordos e convenções coletivas de trabal ho uma ou mais cláusulas referentes à assistência à saúde do trabalhador e de sua família.

D essas, a grande maioria refere-se à assistência médico-hospitalar e, em alguns casos, acresce-se a odontológica. E m um dos documentos mencionou-se, além disso, a psicológica. Q uase todas as cláusulas prevêem a participação de empregados e empresas no custeio do benefício. Há poucos casos em que se define que o gasto com o convênio será de total responsabilidade da empresa e um que atribui as despesas exclusivamente aos empregados.

Em menor número, algumas cláusulas tratam de facilidades para aquis ção de medicamentos, por meio de empréstimos, subsídios ou convênios com farmácias. Em um caso, garante-se o subsídio também à compra de óculos.

Algumas das catego rias profissionais conquistaram subsídio para tratamento odontológi co e uma para a compra e manutenção de aparelhos ortodônticos para os trabalhadores e seus dependentes.

Ainda há um acordo coletivo que assegura condução gratuita, em caso de doença, aos empregados e dependentes que residem em local carente de assistência médico-hospitalar.

Também foram verificadas algumas cláusulas que asseguram a extensão da assistência médico-hospitalar aos dependentes de empregados em situações adversas, como no caso de falecimento ou de demissão do funcionário.

Por fim, foi localizada uma cláusula que assegura um auxílio para trabalhadores com dependentes, destinado a todos os empregados homens casados, às 
viúvas com dependentes, arrimos de família, mães solteiras e mães separadas, a ser pago mensalmente e reajustado nas mesmas condições previstas para os salários da categoria.

Garantias relativas às condi ções de trabal ho - N este grupo foram classificadas cláusulas de natureza bastante distintas: as que tratam diretamente da regulamentação das condições do trabalho, como jornada e ambiente; as que procuram coibir abusos contra as trabalhadoras; as referentes às necessidades fisiológicas da trabalhadora e, por fim, as relativas a exigências com a aparência para 0 exercício da função.

A característica mais marcante desse grupo é o pequeno número de cláusulas verificadas e sua restrição a poucas categorias profissionais.

No que se refere à jornada de trabalho, foram registradas cinco categorias profissionais que incluem esse tema em suas negociações. Três delas referem-se à prorrogação da jornada de trabalho para mulheres e menores, sendo que duas a condicionam à autorização médica anterior e uma a entendimento direto com os empregados com assistência obrigatória do sindicato.

U ma categoria profissional registra que o trabalho feminino em jornada noturna deve ser realizado com os mesmos direitos e nas mesmas condições em que o trabalho masculino.

Ainda foram observadas duas convenções coletivas que, ao estabelecer a flexibilização da jornada de trabal ho, ressaltam a necessidade de se considerar a situação das empregadas mães. Em uma delas, há referência às empregadas que tenham filhos em creches e às gestantes. $\mathrm{N}$ a outra, às empregadas com filhos em idade inferior a sete anos.

Q uanto às condições para o exercício do trabalho, apenas uma assegura à trabalhadora o direi to de exercer suasatividades sentada, quando tal for compatível com as tarefas a serem realizadas.

No que se refere à coibição de abusos contra as mulheres, foram localizados dois tipos de garantia: o de normas para a execução de revista de pessoal, negociada por catorze categorias profissionais e a questão do assédio sexual, incluída nos contratos de apenas uma categoria profissional, a partir de 1996.

Q uanto à revista de pessoal, todos os textos verificados definem que as empresas que adotarem esse sistema o farão em local adequado e por pessoa do mesmo sexo do revistado, para evitar eventuais constrangimentos.

Já o assédio sexual foi mencionado em um dos parágrafos de uma cláusula, recomendando que sejam incluídas a orientação e a conscientização sobre as conseqüências que podem advir da prática de assédio sexual nas campanhas para a mel horia das relações humanas promovidas para encarregados e líderes de produção das empresas.

Ainda dentro do grupo sobre condições de trabalho, foi prevista, por dezenove categorias profissionais, a obrigatoriedade das empresas que empre- 
gam mão-de-obra feminina manterem, na enfermaria ou na caixa de primeiros socorros, absor ventes higiêni cos para ocorrências emergenciais. U ma das categorias profissionais prevê, também, o fornecimento de analgésicos.

Por último, uma categoria profissional ligada ao comércio estabelece que a empresa que exigir das empregadas determinado tipo de sapatos ou meias deve fornecê-los ou substituí-los, sempre que necessário.

Pode-se concluir que as cláusulas relativas às condições de trabalho das mulheres, no geral, referem-se a questões não fundamentais das relações de trabalho, além de serem negociadas por poucas categorias profissionais. A cláusula que prevê o fornecimento de absorventes às trabalhadoras, por exemplo, é acordada por aproximadamente $20 \%$ das categorias, mas não há determinação de obrigatoriedade das empresas em manterem local adequado para a higiene pessoal nem a de proporcionarem intervalos que a viabilizem durante a jornada.

Tampouco o estabelecimento de regras para a continuidade do processo de revista de pessoal, para que sejam evitados "constrangimentos", negociado por $15 \%$ das categorias profissionais, questiona a legitimidade desse procedimento em relação aos trabalhadores.

As garantias de fornecimento de meias e sapatos e o direito a trabalhar sentada são conquistas que se restringem a apenas uma categoria profissional. Até mesmo assédio sexual por parte das chefias, um dos maiores problemas enfrentados pelas trabalhadoras, é mencionado por apenas uma, das 94 categorias pesquisadas.

Garantiasrelativasao exercício do trabalho - N esse tópico foram tratadas as cláusulas relativas à formação profissional da mulher, tanto no que se refere a sua qualificação para o ingresso no mercado de trabal ho como à sua reciclagem.

As garantias sobre qualificação profissional da mulher, de grande importância para o mercado de trabal ho atual, são praticamente inexistentes no material examinado: foi localizada apenas uma cláusula relativa à qualificação e ao treinamento da mulher, negociada por oito categorias profissionais.

0 texto que estabelece a garantia é vago, prevendo que os sindicatos envolvidos no contrato coletivo devem envidar esforços no sentido de que sejam oferecidos, no Serviço N acional da I ndústria (Senai), cursos e oportunidades de aprendizagem e formação para o sexo feminino. Além disso, devem fazer chegar ao conhecimento do Conselho Regional do Senai a reivindicação dos trabalhadores da categoria, a fim de que o Senai proporcione instalações adequadas para aprendizes mulheres.

Garantias relativasà saúde da mulher - O levantamento observou também cláusulas que visam à preservação da saúde da mulher, sem vinculação com a defesa da função reprodutiva.

Também nesse grupo é bastante restrito o número de conquistas e o de categorias profissionais que as incluem em seus contratos: em todo o universo 
pesquisado, foram encontrados três tipos de cláusulas que tratam da saúde da trabalhadora sob essa perspectiva, além das que se referem à Aids.

D uas das catego rias profissionais cujos contratos coletivos são acompanhados pelo SACC - D ieese, asseguram al guma garantia com relação a exames para a preven ção decân cer gi necológi co. U ma garante o custeio anual, pelas empresas, de exames de papanicolau e mamografia das empregadas com mais de quarenta anos. O utras recomendam às empresas que incluam exames e testes de prevenção de câncer ginecológico, por ocasião dos exames periódicos de saúde.

Sete categorias profissionais asseguraram cláusulas referentes à Aids. D uas delas incluíram essas cláusulas em seus contratos durante o período analisado. Q uanto ao conteúdo, a maioria prevê a necessidade de as empresas promoverem ou fornecerem recursos para a promoção de campanhas educativas para a prevenção da doença.

Foi registrado, ainda, um contrato que determina a manutenção e a continuidade dos trabalhos de uma comissão paritária com objetivo de apresentar estudos com vistas a uma política global de prevenção e de assistência e acompanhamento aos trabalhadores portadores de Aids, além de vedar a exigência de exame admissional para pesquisa da presença do vírus da doença.

Além dessas, destacam-se ainda os contratos celebrados por duas outras categorias profissionais. Em um caso, há a previsão de que seja adotada uma política global de prevenção à Aids e que haja acompanhamento dos funcionários soropositivos. N o outro, garante-se estabilidade aos portadores de H IV que vierem a apresentar infecções ou doenças oportunistas em decorrência da Aids.

Ainda foram negociadas garantias de licença e de emprego à trabal hadora que sofrer aborto.

No caso da li cença, apenas uma das categorias profissionais examinadas a negociou, assegurando à trabalhadora quatro semanas de estabilidade, o que significa duas a mais do que prevê a legislação.

Já com relação à estabilidade, oito categorias profissionais constantes do SACC - D ieese a conquistaram, em períodos que variam de trinta a noventa dias.

Por último, no grupo de cláusulas referentes à saúde da mulher, registrouse, em uma única categoria profissional, a obrigatoriedade e a gratuidade de exame médico aos trabalhadores afastados por mais de trinta dias, inclusive às trabalhadoras afastadas por parto, que retornarem de licença-maternidade.

É importante observar que, nesse grupo, são tratadas questões da maior importância para a mulher trabalhadora, na perspectiva física ou emocional e psicológica: 0 câncer ginecológico e 0 aborto. Entretanto, pouquíssimas categorias profissionais conquistam al guma garantia com relação a problemas tão relevantes.

Em que pese a seriedade do tema, para homens ou mulheres, os contratos que contemplam o problema da Aids, embora tenham apresentado uma evolução durante o período, são também ainda muito poucos. 
Garantiasrelativasà eqüi dadedegênero - A pesquisa realizada no SACC D ieese localizou dezesseis categorias profissionais ( $17 \%$ do total) que incluem em seus contratos coletivos uma cláusula que se refere à igual dade entre os sexos, estabelecendo garantias contra discriminação.

A maioria refere-se às disposições legais, reforçando o princípio de igual valor para trabalho igual. N ove referem-se à igualdade de remuneração entre todos os trabalhadores e dois explicitam as diferenças salariais que serão aceitas. 0 utra assegura que haverá igualdade de oportunidade à mulher para concorrer a cargo de chefia e outra, ainda, igualdade de condições de trabalho, salário e progressão funcional. D uas categorias afirmam que não haverá distinção de qualquer natureza.

N o perío do analisado, quatro categorias profissionais passam a incluir cláusulas desse tipo em seus contratos, o que indica uma evolução desse tema no processo de negociação coletiva.

É importante observar que, embora haja um incremento na negociação de questões que explicitam diretamente a idéia da eqüidade de gênero, os resultados das nego ciações coletivas quase nada têm garantido. As cláusulas asseguradas continuam limitando-se a transcrever os dispositivos legais que proíbem a discriminação e não garantem formas de controle ou punição para atitudes ou ações deste tipo. Também ainda não estabelecem formas positivas de ação para a reversão das desigualdades.

\section{Conclusões}

$\mathrm{N}$ o material examinado, foram registradas, para cada contrato coletivo cadastrado, em média, cinco cláusulas que tratam das garantias referentes ao trabaIho da mulher. Em parte das categorias profissionais não consta uma única cláusula sobre o tema, mas, em algumas delas, chegaram a ser encontradas até dez por ano.

A grande maioria das garantias está relacionada à gestação, maternidade e responsabilidades familiares - cerca de $80 \%$ do total. O s outros $20 \%$ estão distribuídos entre os temas condições de trabalho (com 8\%), exercício do trabalho (menos de $2 \%$ ), saúde (em torno de $5 \%$ ) e eqüidade de gênero (próximo a $4 \%$ ).

As garantias mais disseminadas nos contratos coletivos são as regulamentadas por lei e, embora o processo de negociação coletiva tenha assegurado a conquista de diversas cláusulas, estas estão restritas a poucas catego rias profissionais.

E mbora os resultados não apontem para uma melhoria significativa da situação da mulher no mercado de trabalho, é preciso reafirmar a importância da negociação coletiva na regulamentação das relações de trabalho, tanto no que se refere à introdução de garantias ausentes da legislação como à ampliação de direitos já previstos. É nesse processo que se asseguraram conquistas como estabilidade ao pai, liberação para o acompanhamento de filhos, extensão dos prazos legais de estabilidade da gestante e de utilização de creches. 
M esmo quando restritas a poucas categorias profissionais ou com avanços pouco significativos, essas garantias, que são da maior importância no cotidiano dos trabalhadores, abrem espaço para a negociação de questões de gênero e do trabalho das mulheres e possibilitam sua intensificação.

Também é fundamental que não se perca de vista o cenário econômico e social em que essas negociações ocorreram. A década de 1990 caracterizou-se como um ponto de inflexão na trajetória de crescente regulação das relações de trabalho que se constituía. O s direitos do trabalho e, especialmente, a busca pela igualdade social, foram postos em xeque pelas tentativas de desregulamentação empreendidas em todo o mundo, ao longo desse período.

$\mathrm{N}$ esse contexto, mesmo a simples manutenção de garantias já anteriormente conquistadas demanda enorme esforço de organização e resistência das entidades sindicais e a ação empreendida neste processo pode ter sido um obstáculo para uma maior degradação das condições de trabalho.

Assim, se a intensificação da participação da mulher no mercado de trabaIho não garante a ela igualdade de inserção e qualidade de trabalho, a intensificação da luta pela conquista de direitos que apontem para a reversão desse quadro pode traduzir-se no aumento da negociação de garantias relativas à eqüidade de gênero, na introdução, pela negociação direta, de benefícios não regulamentados por lei e, até, pela introdução de temas dessa importância nas mesas de negociação.

\section{N otas}

1 Inclui pessoas que estão sem trabalho e buscam colocação há mais de trinta dias e têm disponibilidade imediata para exercer uma função.

$2 \mathrm{~N}$ esta categoria estão incluídas as pessoas que realizaram, nos sete (ou nos trinta) dias que antecederam a entrevista da PED, trabalhos precários de auto-ocupação - atividades remuneradas eventuais e instáveis ou não-remuneradas em ajuda a negócios de parentes - e que têm procurado substituir este trabalho.

3 R eúne pesso as que não trabal haram na semana anterior à entrevista e nem procuraram ocupação no último mês, por desestímulo do mercado de trabalho ou por circunstâncias fortuitas, mas que real izaram ações concretas de procura de trabalho durante pelo menos quinze dias, nos últimos doze meses, e que estão dispostas a assumir um emprego, caso Ihes seja oferecido.

4 Dieese. N egociação coletiva e eqüidade de gênero no Brasil: cláusulas relativas ao trabalho da mulher: 1996-2000. São Paulo, ago. 2000. (Pesquisa D ieese, 17).

5 Lei 9.799 , de 26 de maio de 1999, que acrescentou ao parágrafo 4o do artigo 392 da C onsolidação das L eis do T rabalho o inciso II, que garante à empregada, durante a gravidez, sem prejuízo do salário, dispensa do horário de trabalho pelo tempo neces sári o para a realização de, no mínimo, seis consultas médicas e demais exames comple mentares 
6 Em 15 de abril de 2002, posteriormente, portanto, ao período aqui analisado, a Lei 10.421 estende às mães adotantes o direito à licença- maternidade e ao salário maternidade, assegurando em 120 dias a licença às adotantes de crianças de até um ano; em sessenta dias às de um a quatro anos e em trinta dias às de quatro a oito anos.

7 Essa cláusula foi retirada do contrato de trabalho da categoria em 1999.

R ESU M o - MU ITos motivos têm levado a mulher para o mercado de trabal ho: a emancipação feminina e a opção por um projeto profissional, o desemprego ou a perda de renda do cônjuge e o crescimento do número de mulheres chefes de famílias. Este ingresso da mulher no mercado de trabalho, no entanto, não tem sido fácil, devido à conjuntura político-econômica dos últimos anos, que tem criado muitas barreiras para todas as pessoas que procuram ocupação.

O utras adversidades, porém, agravam ainda mais a situação da participação feminina no mercado de trabalho. Traduzidas em diversas formas de discriminação, revelam-se por meio de baixos salários, ocupação de postos precários, discriminação na contratação e ascensão, desemprego.

Para mostrar essa inserção diferenciada da mulher do mercado de trabalho, o Dieese reuniu e analisou os resultados das negociações coletivas no país, de 1996 a 2000, sob o enfoque da questão de gênero. O s resultados mostram o quanto ainda é necessário caminhar para condições mais igualitárias entre os sexos e a importância da negociação coletiva na regulamentação das relações de trabalho.

A BSTRACT - FOR MANY reasons, women go to the labour market: emancipation, leading to professional plans; income loss due to spouse' sunemployment or other changes; increases in the number of women heading families. H owever, it has been an uneasy transition, as in the current conjunctural context people looking for a job are experiencing all sort of barriers.

Another dificulties even worse women conditions in the labour market. They have to do with gender discrimination, which leads to low salaries, inequality in employment access and opportunities, unemployment.

To better show this situation, D ieese gathered and analysed the results of collective bargaining in our country, from 1996 to 2000, in the gender context. The results show how far from equality we are referring to gender issues, and the relevance of negotiation as an instrument of collective regulamentation in labour relations.

Solange Sanches é socióloga, graduada na U SP, especialista em economia e em gestão das relações de trabal ho pela PU C-SP, coordenadora de pesquisas do D ieese.

Vera Lúcia M attar G ebrim é socióloga graduada na U SP, supervisora do Banco de Dados Sindicais do D ieese.

Texto recebido e aceito para publicação em 25 de setembro de 2003. 